\title{
CARBOHYDRATE TOLERANCE AFTER PROTAMINE INSULIN : ITS BEARING ON THE PHYSIOLOGY OF INSULIN SECRETION ${ }^{1}$
}

\author{
By HENRY T. RICKETTS \\ (From the Department of Medicine, University of Chicago, Chicago)
}

(Received for publication August 9, 1938)

The question of whether or not the behavior of the blood sugar in the normal organism after a carbohydrate meal depends upon the secretion of extra insulin is one which cannot be answered conclusively until a method is made available for measuring the amount of insulin in the blood stream. There is, however, considerable indirect evidence favoring the theory that normally the ingestion of carbohydrate stimulates the secretion of insulin by the pancreas (1).

In 1934 doubt was cast on the validity of this theory by the work of Soskin, Allweiss, and Cohn (2), who showed that in depancreatized dogs receiving a constant intravenous injection of glucose and insulin so adjusted as to maintain the blood sugar normal and level, an added dose of glucose gave a normal sugar tolerance curve provided the liver was intact. Extra insulin, therefore, was neither available nor required, and it was concluded that the pancreas is not essential to the production of a normal glucose tolerance curve, though, on the basis of further evidence, the liver was deemed necessary.

The first hint that these results, together with their implications, might apply only in the rather special conditions under which they were obtained came from clinical investigations of diabetic patients treated with protamine insulin. It has been the common experience of physicians that in severe diabetes a daily dose of protamine insulin which would render the blood sugar normal before breakfast or during the night would often fail to prevent hyperglycemia after meals (3). Such experiences constitute a parallel fairly close to, but more physiologic than, the experiments with intravenous insulin and glucose in depancreatized dogs. It is apparent in such cases that the constant supply of insulin derived from the subcutaneous depot of protamine insulin, although it is able to take care of the endogenous carbo-

1 Presented in part before the American Physiological Society, April, 1938, at Baltimore, Maryland. hydrate metabolism, needs to be augmented at meal time with extra insulin if the blood sugar is to be kept within normal limits. On the other hand, it is well known that in cases in which the disease is relatively mild the blood sugar can be controlled at all times with protamine insulin alone.

Suggestive as the experiences with severe diabetics were, there remained the possibility that the abnormal behavior of the blood sugar after meals, especially after breakfast, might be owing to the beginning exhaustion of the protamine insulin given the previous morning or to the slow action of the dose given on the morning in question. It was decided, therefore, to obtain blood sugar curves in such patients under more carefully controlled conditions.

Hospitalized patients with diabetes of varying degrees of severity but well regulated with one or the other type of insulin were given, in the morning or evening of one day, a dose of protamine insulin which during the entire morning of the following day, without food, was shown to maintain the blood sugar at a constant normal level. Several days later or earlier in each case, and under identical circumstances, a similar experiment was performed, this time giving the breakfast allowed by the patient's usual diet. Determinations of the blood sugar ${ }^{2}$ were made before and at intervals after the meal. In addition, comparable experiments were carried out in two chronically depancreatized dogs and in one normal dog. The blood sugar time curves and pertinent clinical data are given in the accompanying charts.

\section{DESCRIPTION OF CHARTS}

\section{Severe diabetes}

Patient E. V. (Figure 1). Thirty-five units of protamine insulin given at supper time on June 15, 1937,

2 Analyses were made on capillary blood by the method of Miller and Van Slyke (4). 

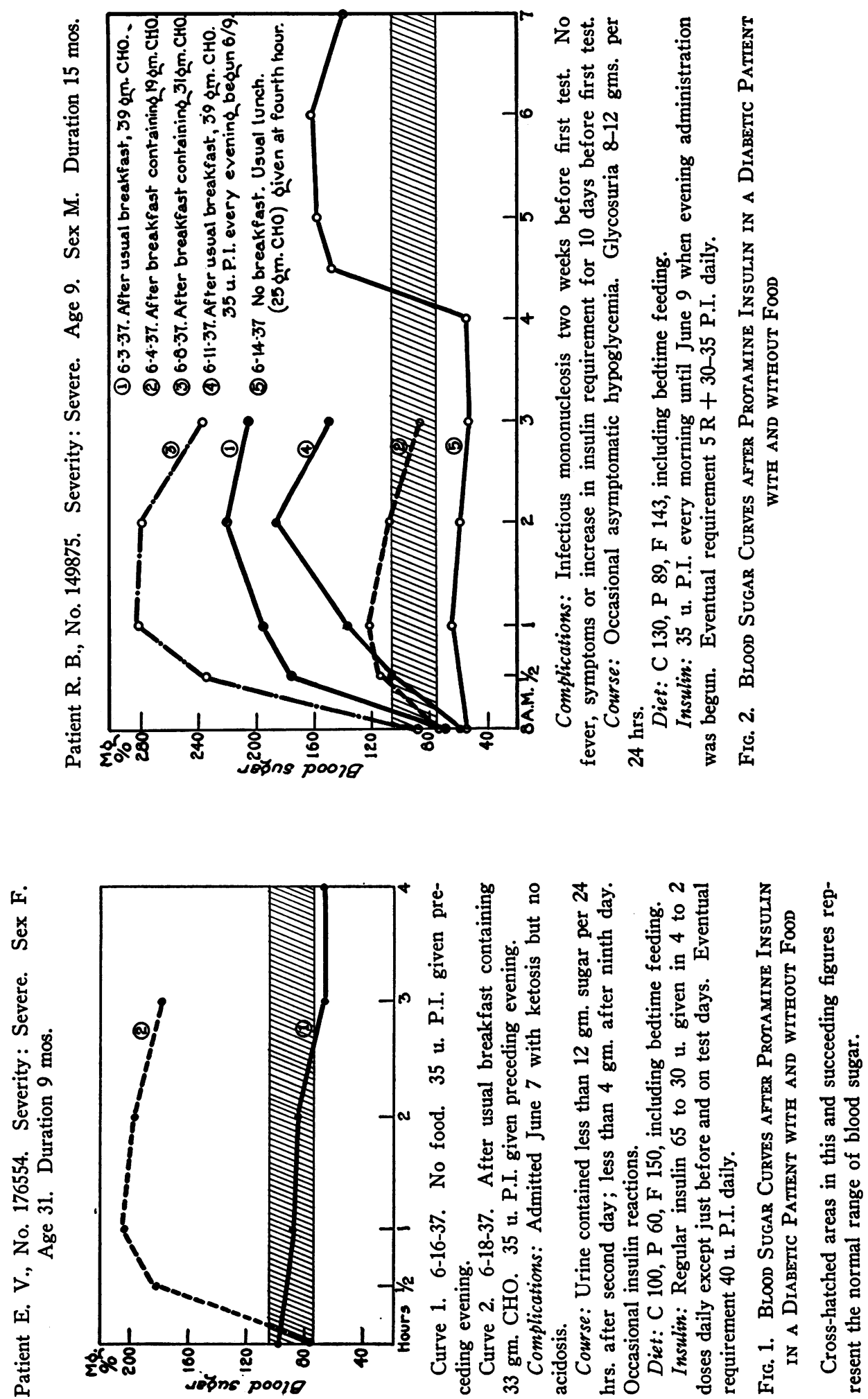
Patient B. S., No. 155131. Severity : Moderate to Severe. Age 65. Sex F. Duration, 7 yrs.

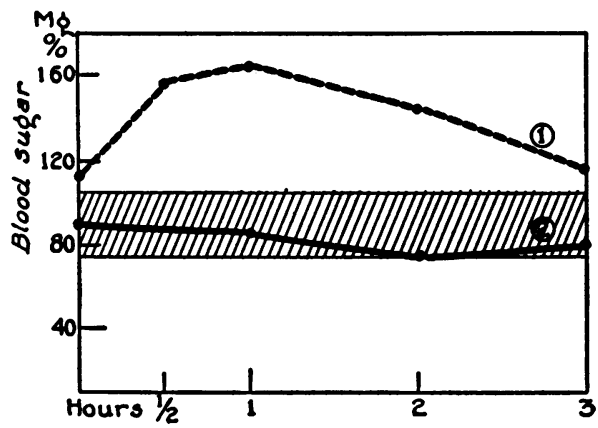

Curve 1. 10-21-37. After usual breakfast, $24 \mathrm{gm}$ CHO. 50 u. P.I. given preceding morning, also this A.M. Curve 2. 10-23-37. No food. 50 u. P.I. given preceding morning.

Complications: Hypertension, Arteriosclerosis.

Course: Sugar-free throughout. No hypoglycemia.

Diet: C 120, P 70, F 139 (including bedtime feeding).

Insulin: 50 u. P.I. given every morning $1 / 2 \mathrm{hr}$. before breakfast except on morning of fast. Eventual requirement 45 u. P.I. daily.

Fig. 3. Blood Sugar Curves after Protamine Insulin in a Diabetic Patient with and without Food

kept the blood sugar normal during the entire morning of June 16 when no breakfast was allowed (Curve 1). The same dose of protamine insulin given at supper on June 17 failed to prevent hyperglycemia after a breakfast containing 33 grams of carbohydrate on June 18 (Curve 2).

Patient R. B. (Figure 2). Curves 1, 2, and 3 were obtained during a period in which the patient was receiving 35 units of protamine insulin every morning onehalf hour before breakfast. When this meal contained 39 grams (Curve 1) or 31 grams (Curve 3) of carbohydrate the glycemic curve was distinctly diabetic, but when only 19 grams of carbohydrate were given (Curve 2 ) the curve was normal. Curves 4 and 5 were obtained after the time of administration of the protamine insulin had been changed from morning to evening. Although 35 units kept the blood sugar fairly constant at an even subnormal level without food during the next morning, the noon meal containing 25 grams of carbohydrate resulted in an unduly prolonged elevation (Curve 5); and on another day, despite a hypoglycemic start, the curve after the usual breakfast containing 39 grams of carbohydrate was abnormal (Curve 4).

\section{Moderately severe to severe diabetes}

Patient B. S. (Figure 3 ). With the patient receiving 50 units of protamine insulin every morning, including the morning of the first test, a breakfast containing only
Patient J. R., No. 176278. Severity : Mild. Sex M. Age 61. Duration 3 yrs.

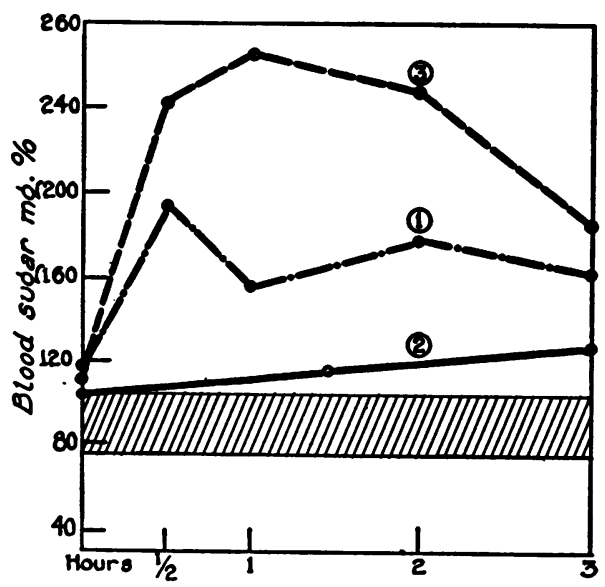

Curve 1. 7-29-37. After usual breakfast, $33 \mathrm{gm}$. CHO. 15 u. P.I. given preceding morning.

Curve 2. 8-3-37. No food. 15 u. P.I. given preceding morning.

Curve 3. 8-5-37. After $33 \mathrm{gm}$. glucose. 20 u. P.I. given preceding morning.

Complications and Course: Early June, 1937, treated for amebiasis with emetine and yatren. July 6, 1937, combined abdomino-perineal resection of rectum for carc. Good recovery. No fever for 11 days before first test. No glycosuria.

Diet: C 100, P 59, F 129.

Insulin: 15 u. protamine zinc insulin $1 / 2$ hour before breakfast every morning except on test days, when same dose was given at conclusion of test. The test with glucose was preceded by $20 \mathrm{u}$. given previous morning. Eventual requirement 20 u. P.I. daily.

\section{Fig. 4. Blood Sugar Curves after Protamine Insulin in a Diabetic Patient with and without Food}

24 grams of carbohydrate still resulted in a blood sugar considerably above normal at the 2 -hour period and slightly above at 3 hours (Curve 1). It was through an error that any insulin was given on this morning, and this, coupled with the fact that it had been necessary to reduce the carbohydrate of the breakfast from 40 grams to 24 grams in order to control glycosuria with protamine insulin alone, may account for the curve's not being more "diabetic" than it is. Curve 2 demonstrates the ability of 50 units of protamine insulin given 24 hours earlier to maintain the blood sugar at a normal level without food.

\section{Mild diabetes}

Patient J. R. (Figure 4). All curves were obtained during a period in which the patient was receiving an injection of protamine insulin each morning before 
Patient F. M., No. 149886. Severity: Mild. Age 69. Sex F. Duration 5 years.

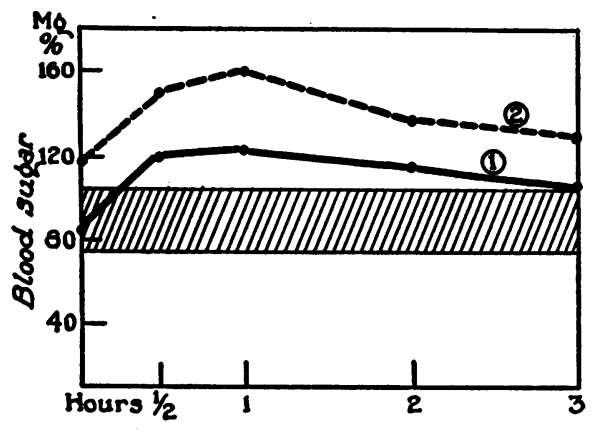

Curve 1. 7-20-37. After usual breakfast, $33 \mathrm{gm}$. CHO. 10 u. P.I. given preceding morning.

Curve 2. 7-26-37. After usual breakfast, $33 \mathrm{gm}$. CHO. No insulin for 4 days.

Complications: Nephrosclerosis, hypertension, generalized arteriosclerosis, diabetic and hypertensive retinitis.

Course: F.B.S. $1936=211$ mg.\%. Sugar free throughout. No hypoglycemia.

Diet: C 100, P 75, F 80.

Insulin: 10 u. P.I. $1 / 2 \mathrm{hr}$. before breakfast each morning except first test day. All insulin stopped July 22 .

Fig. 5. Blood Sugar Curves after Protamine InSUlin in a Diabetic Patient with and without FOOD

breakfast. No insulin, however, was given on any test morning, the dose for that day being given just before lunch and after the conclusion of the test. Curve 1 shows that 15 units of protamine insulin administered 24 hours earlier rendered the fasting blood sugar practically normal but was inadequate to effect a normal response after a breakfast containing 33 grams of carbohydrate. It is to be noted, however, that this curve is not as abnormal as the curves seen in the cases of severe diabetes (Figures 1 and 2) after a similar meal. That the dose of 15 units was a little short of being optimum is shown by the gradual rise of Curve 2, which was obtained under identical conditions except that breakfast was withheld. When the test meal consisted of glucose (Curve 3) in an amount equal to the carbohydrate of the patient's usual breakfast ( 33 grams), the sugar tolerance curve was even more abnormal despite the larger dose of protamine insulin ( 20 units) administered the preceding morning.

Patient F. M. (Figure 5). With the patient receiving a daily injection of protamine insulin, her usual breakfast, containing 33 grams of carbohydrate, resulted in a practically normal blood sugar curve (Curve 1 ). The mildness of her disease is shown by Curve 2, obtained after a similar breakfast but 4 days after withdrawal of all insulin. The fact that the patient was nevertheless diabetic is indicated by the fasting blood sugar of 211 mgm. per cent in 1936 .
Dog A-Diabetic. Sex M. Wt. 7.5 kg. Depancreatized 12-8-37.

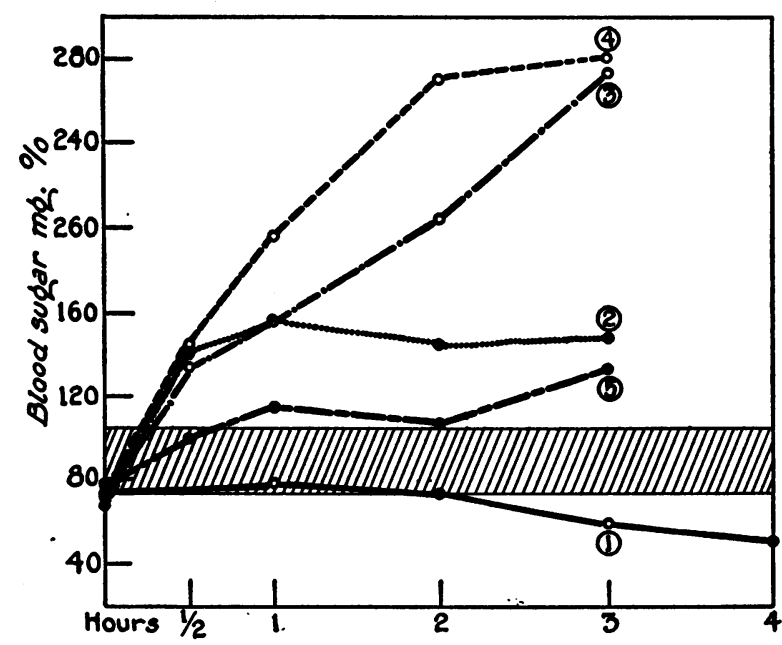

First Experiment: 1-11-38. Wound healed and dog in good condition.

Each blood sugar curve obtained in the morning after a preceding evening dose of 5 u. P.I.

(1) No food.

(2) After usual breakfast, $25 \mathrm{gm}$. CHO.

(3) Same.

(4) After usual breakfast, $12 \mathrm{gm}$. $\mathrm{CHO}$.

(5) Breakfast but no CHO.

Diet: Two daily feedings, 9 A.M. and 6 P.M., each consisting of : $150 \mathrm{gm}$. ground beef heart, $50 \mathrm{gm}$. raw beef pancreas, $25 \mathrm{gm}$. cane sugar, $7 \mathrm{gm}$. cod liver oil, $\pm 4 \mathrm{gm} . \mathrm{NaCl}$.

Insulin: $6 \mathrm{u}$. before each feeding.

Glycosuria: 0 to +t.

Fig. 6. Blood Sugar Curves after Protamine InSulin in a Depancreatized Dog with and without Food

\section{Totally depancreatized dogs 8}

$\operatorname{Dog} A$ (Figure 6). The first of these experiments was performed over a month after complete pancreatectomy when the dog was in good condition and the wound well healed. The animal had maintained its weight and exhibited a moderate glycosuria while receiving two daily feedings as indicated in the chart with 6 units of regular insulin before each feeding. This schedule was adhered to throughout except on the test days, which were never less than two days apart and usually longer. The evening before each experiment 5 units of protamine insulin were given subcutaneously, and no insulin was given on the morning of the test. Curve 1 demonstrates that this dose held the blood sugar normal or below during the entire morning without food.

${ }^{8}$ The author is indebted to Dr. Carter Goodpasture for performing the pancreatectomies. 
Dog B-Diabetic. Sex M. Wt. 10.5 kg. Depancreatized 12-8-37.

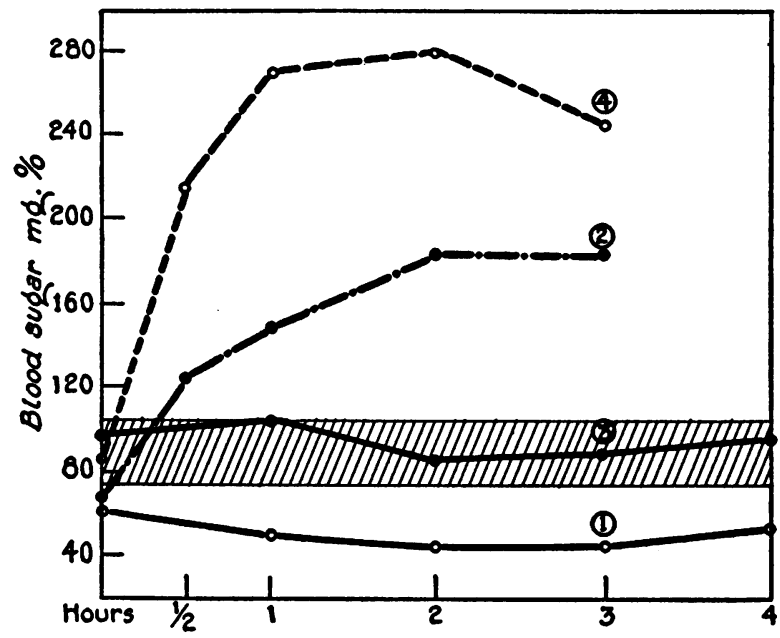

First Experiment, 1-28-38: Wound practically healed at this time, completely healed before next experiment. Dog in good condition.

Curve (1) No food. 3 u. $R+6$ u. P.I. given preceding evening.

Curve (2) After usual breakfast, $25 \mathrm{gm}$. CHO. Insulin as above.

Curve (3) No food. 3 u. $R+4$ u. P.I. given preceding evening.

Curve (4) After usual breakfast, $25 \mathrm{gm}$. CHO. Insulin as above.

Diet: Two daily feedings, 9 A.M. and 6 P.M., each consisting of : $200 \mathrm{gm}$. ground beef heart, $50 \mathrm{gm}$. raw beef pancreas, $25 \mathrm{gm}$. cane sugar, $7 \mathrm{gm}$. cod liver oil, \pm 4 gm. $\mathrm{NaCl}$.

Insulin: $15 \mathrm{u}$. before each feeding.

Glycosuria: 0 to.

Fig. 7. Bloon Sugar Curves after Protamine INSUlin in a Depancreattzed Dog with aNd without FOOD

Curves 2 and 3, obtained after the animal's usual breakfast containing 25 grams of cane sugar, and Curve 4, preceded by a breakfast containing only 12 grams of sugar are all definitely diabetic. The facts that the same amount of sugar in the diet gave different types of curves on different days, and that 12 grams of sugar resulted in greater hyperglycemia than 25 grams, are probably to be explained by differences in absorption. The slight though prolonged rise of Curve 5 illustrates the improved control of the blood sugar by protamine insulin when the source of the dietary carbohydrate is protein instead of preformed carbohydrate.

Five weeks after the last experiment this dog died suddenly in convulsions. Fatty infiltration of the liver was slight in three out of four histological sections but
Dog X-Normal. Wt. 10.7 kg.

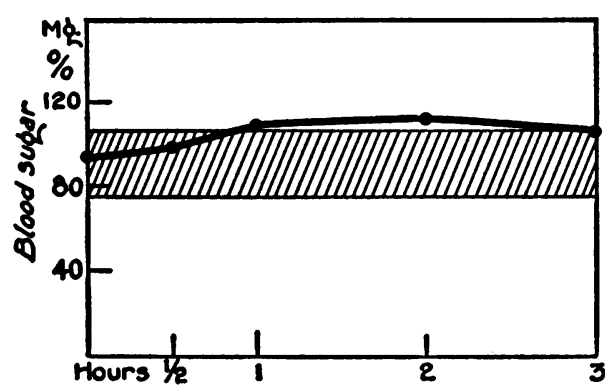

Behavior of blood sugar curve of normal dog fed for two days on diet identical with that for Dog B.

\section{Fig. 8. Blood Sugar Curve in a Normal Dog WITH FOOD}

was marked in two small areas in the last. No pancreatic tissue was found.

Dog $B$ (Figure 7). The experimental procedure was essentially the same as that for Dog A. Curves 1 and 2 show the blood sugar response without and with food respectively after the animal had been given 3 units of regular insulin and 6 units of protamine insulin the evening before each experiment. Since this dose led to hypoglycemia, the observations were repeated using 4 instead of 6 units of protamine insulin (Curves 3 and 4). Both curves obtained after food are clearly diabetic even though Curve 2 starts at a subnormal level.

\section{Normal dog}

Dog $X$ (Figure 8). Dog $\mathrm{X}$ was fed for two days on a diet identical with that used for Dog B. The blood sugar curve obtained after breakfast on the third morning gives no evidence that such a feeding is more than a normal animal of similar weight could be expected to handle adequately.

\section{COMMENT}

It is apparent that in severely diabetic patients and totally diabetic (depancreatized) dogs a dose of protamine insulin capable of maintaining a normoglycemic plateau without food is not adequate to control the blood sugar after a moderate carbohydrate meal. In other words, postprandial hyperglycemia in severe diabetes is not prevented without extra insulin. On the other hand, under similar conditions, the milder the diabetes the more nearly normal is the blood sugar curve. This suggests that the pancreas of the mild diabetic is better able to supply extra insulin at the time it is needed and, further, that the pancreas 
of the normal individual is completely able to do so.

These concepts are in harmony with the theory that, in health, the secretion of insulin is regulated, either directly or through the mediation of the nervous system, by the height of the blood sugar. This theory has definite experimental support. Houssay, Lewis, and Foglia (5) demonstrated that the blood sugar of a normal dog is not altered if as many as three extra pancreases are grafted into its neck, indicating that the secretion of each is depressed and regulated according to the level of the blood sugar. LaBarre (6), Zunz and LaBarre (7), London and Kotschneff (8), Barbas and Schulutko (9), and others have shown that hyperglycemia induced in one animal stimulates the formation of a substance, presumably insulin, obtained from the pancreaticoduodenal vein which, when injected into another animal, lowers the blood sugar of the recipient. Zunz and LaBarre have also shown that hypoglycemia produced in an animal by insulin (10), inhibits the secretion of insulin by that animal.

It may be contended that the arguments presented in this paper that normally there is a pancreatic incretory response to hyperglycemia are based on the hypothesis that diabetes is purely or largely pancreatic in origin and that this theory, in view of the rôle now known to be played by the anterior pituitary, is no longer tenable. It must be pointed out that, whatever the pathogenesis of diabetes, it always exists as a relative insulin deficiency, for the disturbed metabolism which characterizes it can be restored to normal by insulin.

The conclusion that additional insulin is required to bring about a normal return of the blood sugar after a meal is at variance with that reached by Soskin, Allweiss, and Cohn (2) in their work with depancreatized dogs. The difference in experimental results is probably to be explained by differences in experimental procedure. It should be pointed out that what an animal can be made to do under artificial conditions and what it actually does as a matter of everyday existence are not necessarily the same thing. The experiments of Soskin and his coworkers may fall in the former category. It is possible that the constant injection of glucose and insulin given in order to maintain the blood sugar at a normal level for an hour before the administration of the test dose might so accelerate the metabolism of carbohydrate that the addition of more glucose would produce only a moderate disturbance of the equilibrium.

Evidence for such a supposition is to be found in the tests performed in the case of Patient M. S. (Figure 9). In this case of moderately severe diabetes, as in other similar cases described above, a diabetic glucose tolerance curve was obtained after the fasting blood sugar had been brought to normal by protamine insulin given the preceding evening (Curve 1). Five days later, after a similar dose of protamine insulin given the previous evening, the patient received a continuous intravenous injection of glucose and insulin in such proportion as might be expected to maintain the blood sugar normal and level. At the third hour an oral glucose tolerance test was performed, the intravenous injection being continued to the end of the experiment. The resulting blood sugar curve (Curve 2 ) is essentially normal in shape, though, owing to a slight excess of insulin over glucose in the intravenous fluid, it begins and ends at subnormal levels. While this experiment does not determine whether the nor-

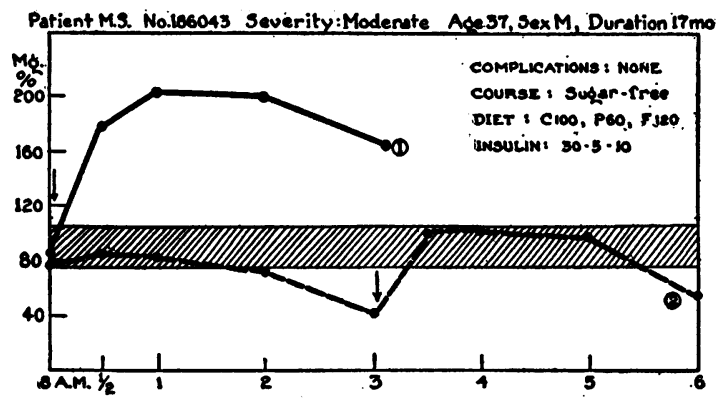

Fig. 9. Glucose Tolerance Curves in a Diabetic Subject (1) After Protamine Insulin and (2) During Continuous Intravenous Injection of Glucose AND INSULIN

Arrows indicate administration of $\mathbf{3 3}$ grams of glucose by mouth.

Curve 1. 25 units of protamine insulin and 5 units of regular insulin given before supper the previous evening.

Curve 2. Protamine and regular insulin given the previous evening as before. At 8 a.m. a continuous intravenous infusion was begun, delivering 0.2 gram of glucose and 0.1 unit of regular insulin in $1.0 \mathrm{cc}$. of fluid per kilogram per hour. The injection was maintained throughout the experiment. 
mality of the second tolerance curve is caused by the effect of preliminary glucose and insulin or possibly by the effect of extra insulin alone, it demonstrates that the shape of the curve in a diabetic subject can be altered toward the normal by this technic. It is maintained that the use of protamine insulin alone in such experiments permits a closer approximation to the normal metabolic status and that the results so obtained, therefore, have greater physiological significance.

The studies here reported do not in any way detract from the importance of the concept, emphasized by Soskin, that the homeostatic mechanism of the liver plays a large part in the regulation of the blood sugar. They indicate, however, that, normally, the proper functioning of this mechanism, when it is presented with the added burden of ingested carbohydrate, depends upon the availability of extra insulin.

\section{SUMMARY AND CONCLUSIONS}

1. It is shown that in severe diabetes, with the fasting blood sugar brought to normal by protamine insulin, postprandial hyperglycemia is not controlled without extra insulin.

2. Under similar conditions the blood sugar curves of mild diabetics approach the normal.

3. These facts do not support the contention that the liver operates to reduce hyperglycemia without the aid of extra insulin. They do offer new evidence in favor of certain old theories, namely :

(a) That normally the ingestion of carbohydrate stimulates the secretion of insulin by the pancreas.

(b) That the pancreas of the severe diabetic responds poorly to such a stimulus.

(c) That the pancreas of the mild diabetic retains enough of its incretory function to react when so stimulated by secreting an additional, though still not optimum, amount of insulin.

(d) That the blood sugar curve of the normal individual may be regarded as the result of a completely adequate pancreatic response.

\section{BIBLIOGRAPHY}

1. Houssay, B. A., Diabetes as a disturbance of endocrine regulation. Am. J. M. Sc., 1937, 193, 581.

2. Soskin, S., Allweiss, M. D., and Cohn, D. J., Influence of the pancreas and the liver upon the dextrose tolerance curve. Am. J. Physiol., 1934, 109, 155.

3. Ricketts, H. T., Problems connected with the use of protamine-zinc-insulin. Ann. Int. Med., 1937, 11, 777.

4. Miller, B. F., and Van Slyke, D. D., A direct microtitration method for blood sugar. J. Biol. Chem., 1936, 114, 583.

5. Houssay, B. A., Lewis, J. T., and Foglia, V. G., Action compensatrice ou préventive de la greffe pancréatique sur la glycémie diabétique ou normale. Compt. rend. Soc. de biol., 1929, 100, 140.

Action de la greffe pancréatique sur les variations de la glycémie produites par l'injection de glucose. Ibid., 1929, 100, 142.

6. LaBarre, J., Les variations insulino-sécrétoires au cours des hyperglycémies extrapancréatiques. Compt. rend. Soc. de biol., 1931, 106, 1247.

7. Zunz, E., and LaBarre, J., Sur l'augmentation de la teneur en insuline du sang veineux pancréatique après l'hyperglycémie provoquée par injection de glucose. Compt. rend. Soc. de biol., 1927, 96, 421.

8. London, E. S., and Kotschneff, N. P., Inkretionsdynamik. II. Utber einige physiologische Anreger der Inkretion der Bauchspeicheldrüse und der Nebennieren. Arch. f. d. ges. Physiol., 1931, 228, 533.

9. Barbas, M. J., and Schulutko, J. B., Die experimentelle inkretorische Analyse als Indicator der Schwere der diabetischen Affektion. Ztschr. f. d. ges. exper. Med., 1935, 95, 729.

10. Zunz, E., and LaBarre, J., L'hypoglycémie insulinique diminue-t-elle la production d'insuline par le pancréas? Compt. rend. Soc. de biol., 1927, 96, 1045. 